\title{
External information processing versus property ascertaining: a discourse-pragmatic study of three yes/no question particles in Shishan (Hainan Island, China) ${ }^{\star}$
}

XUEHUA XIANG

Abstract

Drawing on naturally occurring conversation, the present study examines three utterance-final yes/no question particles, mi, o, and ang, in Shishan, a dialect of Lingao of the Tai-Kadai language family, spoken on northern Hainan Island (China). Both mi and o signal the proposition as deriving from an external information source (primarily preceding discourse). Mi marks simple, linear knowledge accruement/thought progression, based on external information, including plain registration of new information and simple inference. $\mathrm{O}$ signals conflicts between externally derived information vis-à-vis the speaker's pre-existing knowledgelexpectation. Ang constructs a genuine query for unknown information, ascertaining whether the quality/characteristic, as coded in the predicate of the utterance, can ascribe to (i.e., ascribable as a property of) the entity represented by the sentential subject. The meaning of "property ascertaining" gives rise to the use of ang in various presequences (cf. Schegloff 1988).

Keywords: yes/no question; question particle; speaker stance; Lingao; Shishan.

\section{Introduction}

Yes/no question particles are a typological feature of diverse languages, particularly East and Southeast Asian languages (e.g., Cantonese $m \bar{e}$ and àh, Matthews and Yip 1994; Japanese ka, Hinds 1984; Itani 1993; Lao boo; Vietnamese không, McClive 2002; Enfield 2007; Mandarin ma, Li and Thompson 1981, 1984; Russian razve and -li, Comrie 1984; Singapore Teochew -ka, Cole and Lee 1997; Taiwanese kám, bo, Cheng 1977; Thai /máy/,/rú/, Iwasaki and Ingkaphirom 2005; West Flemish da, Haegeman 1993; among others). 
Cross-linguistically, yes/no question particles not only signal the interrogative mood, but also evince pragmatic/semantic subtleties reflecting the speaker's understanding of, and attitude toward, the questioned proposition, the interlocutor's knowledge state, aspects of the previous discourse, and other contingencies of the interactional context.

Using six hours of naturally occurring conversation in Shishan, a dialect of Lingao of the Tai-Kadai language family, spoken on northern Hainan Island, China (Strauss and Xiang 2009; Xiang 2006, 2009, 2011), the current study examines three utterance-final yes/no question particles, mi (falling tone), $o$ (rising tone), and ang (rising tone).

Both $m i$ and $o$ formulate questions whose propositional content derives from information available in the interactional context (primarily prior discourse). $M i$ indexes a simple, linear knowledge advancement/thought progression based on external information processing. $O$ signals epistemic conflicts between externally derived information and the speaker's pre-existing knowledge.

Ang, on the other hand, forms "original questions" whose proposition constitutes new discourse content (Bolinger 1957: 10-11). Particularly, ang ascertains whether a certain characteristic/situation, encoded in the predicate of the question, is applicable to (i.e., ascribable as a property of) the sentential subject (cf. "ascriptive predicate," Lyons 1977). The meaning of "property ascertaining" is a linguistic resource through which the speaker establishes a factual basis, preparatory for subsequent action. In effect, ang launches various "presequences" (Schegloff 1988).

\section{Yes/no question particles across languages}

A yes/no question may hold the questioned proposition as entirely unknown. The "plain auxiliary questions" in English ("Is he coming?" Bolinger 1957: 24) tend to mark such nonassertive, genuine information-seeking queries. However, among languages, question particles solely for this purpose are rare. For one instance, Thai /máy/ marks a genuine request for information for which the speaker claims no access; thus, /máy/ tends to occur in inquiries of the hearer's "emotions, sensations, perceptions, and desires" (Iwasaki and Ingkaphirom 2005: 279-280). Documentation identifies similar nonassertive question particles: Serbo-Crotian da-li (Rakic 1984), Taiwanese bo (Cheng 1977), and Vietnamese không (McClive 2002).

The so-called "general-purpose question particles" (Matthews and Yip 1994: 311) are more common, such as Mandarin ma, Taiwanese kám, and Japanese $k a$. These particles encode the interrogative mood, wherein the speaker's epistemic/affective biases toward the questioned information are subject to linguistic/interactional specification. For instance, the speaker may express 
epistemic/affective biases through the co-presence of negation, stress/pitch, and stance-marking adverbials (Cheng 1977; Itani 1993; Li and Thompson 1981, 1984).

Certain yes/no questions encode the speaker's epistemic/affective bias toward the questioned information (Bolinger 1957; Quirk et al. 1985). Romero (2005) divided epistemic bias into two types: Type I centers on the speaker's independent belief. The pre-posed negation in English yes/no question ("Isn't it raining?") signals independent knowledge and previous belief. Positive yes/ no questions with the adverb "really" signal a similar bias that "the speaker originally believed the correct answer . . . to be in the negative" (2005: 352).

Type II epistemic bias is "contextual evidence bias" (2005: 352), resulting from the speaker's spontaneous interpretation of contextual evidence. For example, the speaker perceives someone arriving in a dripping raincoat, and asks, "Is it raining?" (2005: 352). ${ }^{1}$

Type I and Type II biases may intertwine in question particles. West Flemish $d a$ and Russian razve provide parallel examples:

(1) a. (Haegeman 1993: 111, originally no. 1a)

Goa-j a weg, da?

'Are you leaving, $d a ?$ ?'

b. (Comrie 1984: 22, originally no. 23)

Razve ty uezžaeš?

Q you leave

'Are you leaving?'

Drawing on relevance theory (Sperber and Wilson 1995 [1986]), Haegeman (1993: 113) proposed that $d a$ encodes a conflict between knowledge/ expectation from the speaker's "cognitive environment" and evidence arising "in the external environment." In example (1a), the speaker notices a guest's packing, an inferential clue of an imminent departure, an otherwise unanticipated action. This device is parallel to Russian razve (example [1b]). Comrie (1984: 21) suggested that razve signals that "the questioner has a certain prior expectation; some piece of new information leads the questioner to believe that this prior expectation may be wrong."

The current study analyzes three yes/no question particles in Shishan, $m i$, $o$, and ang. ${ }^{2}$ Both $m i$ and $o$ formulate a proposition based on reception/ interpretation of external information, thus both encode "contextual evidence bias" (Romero 2005). Mi and $o$ differ in the processing of contextual evidence: $m i$ marks simple, linear thought progression from external information processing. $O$, similar to West Flemish $d a$ and Russian razve, registers new information as conflicting with existing knowledge. Ang constructs nonassertive, information-seeking questions, focusing on property ascertaining, that is, whether the characteristic/situation described in the predicate of the utterance 
is applicable to (i.e., ascribable as property of) the entity represented by the sentential subject. The semantics of "property ascertaining" is a linguistic resource through which the speaker establishes factual basis for subsequent action. As such, ang is instrumental in launching various "presequences" (cf. Schegloff 1988).

\section{Data and methodology}

The data for the present study consist of six hours (from a sixty-hour corpus) of naturally occurring conversations, collected in Shishan Town in 2002 from six business locations, including a hair salon, a dressmaker's shop, a roast duck vendor's stand, a convenience store, a noodle restaurant, and a fruit vendor's stall. Video/audio recording occurred at all sites, except at the roast duck vendor's stand, which produced only audio recordings. The yield is a range of colloquial discourse genres (service encounters, chats, gossip, among others).

The data transcription follows a modified version of conversation analysis (CA) conventions (Atkinson and Heritage 1984), which visually depict the paralinguistic features of the delivery of speech (e.g., pauses, restarts, sound stretches).

Romanization of the Shishan data follows, largely, the Pinyin system, the Romanization system developed for Mandarin Chinese in the People's Republic of China ( $\mathrm{Li}$ and Thompson 1981: XVI). ${ }^{3}$ Modifications accommodate sounds peculiar to Shishan, such as consonant clusters (dlou 'we') and final stops (aop 'five'). Omitted tones do not affect discourse-level analysis.

Instances of the three particles, $m i, o$, and ang, are counted. ${ }^{4}$ Discourse characteristics of the utterances are coded according to whether the utterance (i) contains negation; (ii) contains assertive adverbials (e.g., $a h$ 'still, also, yet'; $\mathrm{ga}$ 'already'); (iii) functions rhetorically; (iv) constitutes verbatim repetition of the interlocutor's previous turn; (v) is subclausal (including vocatives, address terms, noun phrases, or strings of particles); (vi) is a stand-alone particle occupying the entire turn.

Building on the frequency distributions and discourse characteristics of the particles, the study analyzes the moment-by-moment interaction facilitated by $m i, o$, and ang. Particular attention accrues to analytically comparable segments.

\section{Analysis: $m i, o$, and $\operatorname{ang}^{5}$}

Among the three particles, $m i$ is the most frequent, occurring 157 times. $O$ and ang occur 33 times and 40 times, respectively. Table 1 summarizes the fre- 
Table 1. Frequencies

\begin{tabular}{|c|c|c|c|}
\hline & $m i$ & $O$ & ang \\
\hline Hair Salon & 13 & 8 & 4 \\
\hline Dressmaker's Shop & $\begin{array}{l}28 \text { ( } 9 \text { in service encounter, } \\
\text { all by dressmaker) }\end{array}$ & 6 & 4 \\
\hline Duck Vendor & $\begin{array}{l}46 \text { ( } 43 \text { in service encounter, } \\
35 \text { by vendors, } 8 \text { by } \\
\text { customers) }\end{array}$ & $\begin{array}{l}3 \text { ( } 2 \text { in service } \\
\text { encounter, } 1 \text { by } \\
\text { vendor, } 1 \text { by } \\
\text { customer) }\end{array}$ & $\begin{array}{c}22 \text { (19 in service } \\
\text { encounter, } 16 \\
\text { by vendors, } 3 \\
\text { by customers) }\end{array}$ \\
\hline Noodle Restaurant & 34 & 10 & 9 \\
\hline Convenience Store & $\begin{array}{l}31 \text { ( } 1 \text { in service encounter, } \\
\text { by store-owner) }\end{array}$ & 4 & 0 \\
\hline Fruit Vendor* & 5 & 2 & 1 \\
\hline Total & 157 & 33 & 40 \\
\hline
\end{tabular}

* The comparative paucity of particles in the data from the fruit vendor relates to long stretches of silence among people present.

quencies of these particles, with particular identification of tokens in service encounters, from the business owner versus customers.

The high frequency of $m i$ is unsurprising. The marking of simple, linear processing of external information facilitates two main types of action: plain registration of new information and simple inference. Such information-driven thought progression/knowledge advancement is a typical facet of spontaneous conversation where information exchanges occur in abundance. Encoding incongruity between externally derived information and established knowledge, the marked meaning of $o$ accounts for its low frequency.

The low frequency of ang relates to its core meaning, a property-ascertaining device, seeking unknown information preparatory to action. This specificity in meaning explains the scant appearance of ang in the six datasets, except its frequency in the data from the roast duck vendor's stand (where the $m i$ to ang ratio is $2: 1$; the overall $m i$ to ang ratio at 4:1). The meaning of "property ascertaining" facilitates vendors' probing customers' purchasing desires and customers' ascertaining product qualities before purchases (details are in Section 4.3).

The distinctions of ang versus $m i$ and $o$ are also manifest in the discourse characteristics of the questions they mark. Table 2 describes two types of discourse characteristics: features (a), (b), and (c) focus on the co-presence of stance-expressing constructions (e.g., assertive adverbials, negation, and rhetorical use). Features (d), (e), and (f) concern whether the proposition is subclausal, an indication that part of the proposition is "contextually given" (Bolinger 1957: 24-25).

Assertive adverbials such as $g a$ 'already' co-exist with one-fifth of either $m i$ or $o$ tokens, but none co-exist with ang. In addition, nearly a third of $m i$ and $o$ 
Table 2. Discourse features

\begin{tabular}{llll}
\hline Discourse characteristics & $m i$ & \multicolumn{1}{l}{ Ang } \\
\hline a. co-occurrence with negation & $54 / 157(34.4 \%)$ & $11 / 33(33.3 \%)$ & 0 \\
b. co-occurrence with assertive adverbials e.g., & $32 / 157(20.4 \%)$ & $7 / 33(21.2 \%)$ & 0 \\
ah 'still', ga 'already' & & & \\
c. functioning as rhetorical questions & $25 / 157(15.9 \%)$ & $4 / 33(12.1 \%)$ & 0 \\
d. verbatim repetition of previous turn & $13 / 157(8.3 \%)$ & $5 / 33(15.2 \%)$ & 0 \\
e. subclausal proposition & $28 / 157(17.8 \%)$ & $1 / 33(3 \%)$ & 0 \\
e.g., bok mi? '(so you want to buy) the duck?' & & & \\
f. stand-alone & $3 / 157(2.0 \%)$ & $3 / 33(9.1 \%)$ & 0 \\
e.g., mi? 'Is that so?' & & & \\
\hline
\end{tabular}

tokens occur with negation, none with ang. As Givon (2005: 372) suggested, negated propositions are a "speech act" of "correcting [...] misguided beliefs." The fact that ang only occurs in affirmative propositions indicates that ang is distinct from the milo pair. While the milo pair signals changes in the speaker's thought/knowledge following informational input, ang initiates and ascertains new content.

Further, both $m i$ and $o$ may append to subclausal utterances where part (or even the entirety) of the proposition is contextually given. In contrast, ang questions contain at least a verbal/adjectival predicate (which Bolinger [1957: 25] calls "full questions").

\subsection{Mi: simple, linear processing of external information}

$M i$ marks a simple, linear processing of external information (primarily prior discourse). In interaction, manifestation of the process is (plain) registration of new information in the speaker's active consciousness (Chafe 1994), or simple inferences (linear thought progression). ${ }^{6}$ Examples (2) and (3) provide illustrations.

(2) ((M is in the dressmaker's shop. G, a relative of M, enters the shop. Prior to this segment, acting as proxy for the dressmaker, $\mathrm{M}$ uttered a few purchase elicitations. Then, $\mathrm{M}$ invites $\mathrm{G}$ to sit.))

1 M: Ou eii heeee: $:: h$ ? [implicit invitation to chat] sit PRT PRT

'Sit, okay?'7

2 G: $R a$ hia^ nia eydei.

$1 \mathrm{SG}$ just come now

'I've just come (to the market) now (=I can't stay.).'

$3 \rightarrow$ M: Mo hia nia eydei mi::? [plain registration of information]

2SG just come now MI

'You've just come now?' 
Chi: eii suan-fu dlouahdli lo^ la no^.

little PRT daughter-in-law 1PL also M into PRT PRT

'After a while, our (=my) daughter-in-law will also be here.'

(0.6)

Da kurua::a?

cut clothes PRT

'Have new clothes made?'

((The dressmaker joins the talk.))

Following M's invitation to $G$ to sit (i.e., to chat with $M$ ), $G$ states that she has just come to the market, which effectuates implicit rejection of M's invitation to chat. The $m i$-marked question is a verbatim repeat of G's prior turn (line 3) functioning as information receipt. As the exact information has just been given, confirmation is barely necessary. $\mathrm{M}$ continues her turn (line 4) without waiting for a response, informing $\mathrm{G}$ of another family member's impending arrival (possibly hinting to $G$ that she may want to revisit later). After 0.6 second, $\mathrm{M}$ resumes acting as proxy for the dressmaker. As such, the mi-question marks plain receipt of new information and acknowledges G's rejection of the offer to chat.

The following segment contains $m i$ in a simple inferential act.

(3) ( $(\mathrm{K}$, who is pursuing a Master's degree in the US, has returned to Shishan to visit. $\mathrm{BC}$ owns the noodle restaurant. Prior to this segment, $\mathrm{BC}$ learns that K primarily speaks English in the US.))

1 BC: Donggo mang wendu ziayo en-eey de kuaizi dia go na

Chinese fear language identical PL-PRT COP able yo e::r?

write thing DEM type PRT

'(I suspect) your (English) language is as good as (your) Chinese, (you can) write (in English) and stuff like?'8

2 K: Ah de kim dligi vei ey na shiang

AH COP must M several year PRT only

liuli ay lah.

be:considered fluent able PRT

'It has to be several years before one is considered fluent.' (=I

have only been in the US for a year. I don't claim English

fluency.)

$3 \rightarrow \mathrm{BC}:$ Pei mo kao gen ey mo n go ho yingwei duanko mi? [SIMPLE INFERENCE]

when 2SG test up PRT 2SG NEG COP study English major MI '(So) when you passed the college-entrance exam (=when you went to college), you were not English major?' 
4 M: $\quad N$ go, ge de ying- ge de yingwei duanko pei lah.

NEG COP 3SG COP English 3SG COP English major time PRT

'No, of course he was an English major at that time.'

5 BC: Mo de dli hao dou.

2SG COP M easy know

'It should be easy for you to know (English).'

When $\mathrm{BC}$ conjectures that $\mathrm{K}$ must be as proficient in English as in Chinese (line 1), K counter-asserts the need for several years before claiming English proficiency (line 2). BC's subsequent $m i$-question has an inferential connection with K's prior statement, from the logic that K's not claiming proficiency in English belies his not being an English major, which would require years of studying English. When M counters BC's inferential assertion (line 4), BC explicitly states his logic (line 5). That is, if $\mathrm{K}$ had been English major, English should be easy for K (negating K's reason for lack of English proficiency now).

Both plain registration of new information and simple inference are instrumental in service encounters. Business owners use $m i$ to confirm particulars of a customer's purchase request, and the customer uses $m i$ to verify items/prices available for purchases. Among the $157 \mathrm{mi}$ tokens, 53 occur in service encounters (43 occur from the roast duck vendor). Eight $m i$ tokens are from customers, verifying quantity available (ben mo lou mi? '[So there were] just two left?'), or absence of a particular product (mo n meng tu-ka yin mi? '[So] you don't have pig's feet for sale?').

Business owners' use of $m i$ in service encounters tend to occur after the placement of an order. Mi checks specifics of the order, such as the quantity desired (ao piang-a mi? '[So you] want half [of the meat]?' and value (aop mo $m i$ ? '[So you want] five dollars-worth?').

$M i$ may appear at the onset of a service encounter to elicit purchases. Unlike ang, which elicits a purchase by treating the customer's purchasing intention as unknown (elaborations are in Section 4.3), $m i$ expresses an inference of the customer's (lacking) purchasing interest, illustrated in example (4).

(4) $((\mathrm{C} 3=$ customer no. $3, \mathrm{VR}=$ vendor $))$

1 C3: ((addressing a third party))

Ge bei rahey la.

3SG go home PRT PRT

'She/he has gone home.'

$2 \rightarrow$ VR: $\quad(($ addressing C3))

Dou n ao nan mi?

2PL NEG bring meat MI

'(So) you don't want (to buy) meat?' 
3 C3: ((still addressing the third party))

Ge ga bei rah ey la.

3SG already go home PRT PRT

'She/he has already gone home.'

4 ((now addressing VR)) Heh?

okay

'What?'

$5 \rightarrow \mathrm{VR}: \quad N$ ao nan vennei mi?

NEG want meat today MI

'Don't want (to buy) meat today?'

6 C3: (indistinct)

7 VR: Nia.

come

'Come.'

((Subsequently, C3 inquires of a particular meat's availability.))

Observing C3's conversational preoccupation with a third party, VR's mi projects an inference that $\mathrm{C} 3$ does not intend to purchase meats on that particular day (lines 2 and 5). This inference presses for a confirming response and successfully elicits C3's attention (line 4).

A portion of $m i$ tokens constitutes rhetorical questions, i.e., utterances in interrogative form, but function as assertions of reversed polarity (Koshik 2002; Quirk et al. 1985: 825). In these rhetorical uses, superficially, the $m i$ question signals a simple thought progression or advancement in knowledge based on the interlocutor's prior turn. However, common knowledge exposes the absurdity/non-factuality of the ostensibly plain inference. This dual meaning may render a mischievous, tongue-in-cheek rhetorical effect, illustrated in example (5).

(5) ((Customer no. 33 waits for a roast lamb vendor, and chats with the roast duck vendors AS and VR.))

1 C33: Ra ho ge gang, dli gang ao wu, 1SG know 3SG say $M$ say bring out 'I know he said he would bring (the lamb) out.'

$2 \quad N$ ao ranggei lou.

NEG bring how PRT

'He still hasn't brought (the lamb) out.'

3 Ge gang ge pao ge na ao wu.

3SG say $3 \mathrm{SG}$ prepare $3 \mathrm{SG}$ only bring out

'He said he (needed to) cook (the meat), and only then would he bring (it) out.'

$4 \rightarrow \mathrm{AS}: \quad$ Go $::$ :. dli na wu nia yin me $\mathrm{sa}^{\wedge \wedge} n \mathrm{mi}^{\wedge}$ ?

sure $\quad \mathrm{M}$ only out come sell night meal PRT 


\section{'Sure, (so) he's only gonna bring the lamb out for Night} Meal?'

5 C33: Whei, ge lo lu peigen wulou^.

INT 3SG into from then $3 \mathrm{SG}$ NEG out PRT

'Hey, he hasn't come out since when (I saw him).'

Duidiao ge meng ge na $n$ wu leh.

probably 3SG have 3SG only NEG out PRT

'Probably only (because) he has (the meat to prepare), he is not out.'

7 $\rightarrow$ VR: Ge dli bei ne er^^? hehheh ((chuckling))

3SG M go where PRT

'Where can he be? (How puzzling.)'

This episode occurred around 5:30 p.m. when most roast meat vendors have finished selling. C33 appears adamant in his wish to purchase roast lamb. His logic is straightforward: Since the lamb vendor has not arrived at the market, he must still be cooking the meat (lines 1-3). Both AS and VR mock C33, first through a mi question (line 4) and then through a wh- question (line 7); chuckles accompany the latter. The mi-question has a plain, information-processing façade (co-locating with the agreement marker, go 'sure' and the questioned proposition apparently derives from C33's prior turn). However, the inference is absurdity itself, since Shishan has no Night-Market to which "Night Meal" caters. No sensible roast meat vendors would prepare meats for the nonexisting "Night Meal" customers.

C33 avoids committing himself to absurdity by not responding to the question and adamantly re-states his logic-based interpretation of the lamb vendor's absence (lines 5-6). VR joins AS's "tongue-in-cheek" playfulness, with a rhetorical wh- question (line 7) which feigns innocent curiosity toward the lamb vendor's whereabouts, as if puzzled as C33 is.

Throughout the data, the 157 tokens of utterance-final $m i$ complete a range of discourse and pragmatic functions that center on the core meaning of simple, linear information processing. Other interactional functions include, for example, displaying comprehension of prior talk, co-constructing an unfolding narrative, and formulaic greetings (e.g., nia ho mi? 'come-market-mi=so you've come to the market?'). Central to these functions is the dynamic cognitive process, which recruits external information into the speaker's active consciousness at the moment of speaking.

\section{2. $\mathrm{O}$ : external information processing and epistemic incongruity}

$O$ displays many similarities to $m i$ : both derive a proposition from processing externally available information (primarily prior discourse). Both may occur 
with negation, co-locate with assertive adverbials, function as rhetorical questions, appear in verbatim repeats of the previous turn, and append to various subclausal utterances (see Table 2).

Although similar to $m i$ as a marker of external information processing, $o$ deflects externally derived information against the speaker's existing knowledge highlighting incongruity. Thus, $o$ expresses the speaker's stance of surprise, a common stance among diverse languages, exemplified by question particles, such as Russian razve (Comrie 1984) and West Flemish da (Haegeman 1993); by evidentials, such as Turkish -mis (Slobin and Aksu-Koç 1982) and Korean -kwun (Strauss 2005), and by discourse markers, such as English oh (Heritage 1984). Example (6), where one speaker alternates between $o$ and $m i$, is illustrative.

(6) ((Prior to this segment, $M$ asked her son, $K$, to find his father.))

$1 \mathrm{~K}: \mathrm{Ra}$ rangchong dei dlou ge^?

1SG how look.for reach 3SG

'How can I find him?'

$2 \quad$ Ge roh ne? ra [ra:...:

3SG at where I I . . .

'Where is he? I- I-'

$3 \mathrm{M}: \quad[\mathrm{Heh}$ ?

what

'What?'

$4 \rightarrow \quad$ Ge $\boldsymbol{n}$ bei po-sa $\boldsymbol{o}^{\wedge}$ ? [inference + surprise]

3SG NEG go house-tea $\mathrm{O}$

'He is not at the teahouse?'

$5 \mathrm{~K}$ : Guo $\mathrm{so}^{\wedge}$ hiu dei geyin $\mathrm{no}^{\wedge}$, brother big just.now look.for $3 \mathrm{SG}$ completely PRT

'Big Brother just looked for him everywhere.'

$6 \rightarrow$ M: Dei $n$ dlou ge mi? [simple inference]

Look.for NEG RES 3SG MI

'Didn't find him?'

7 K: Heh.

Yes

'Yes.'

The propositions in both $m i$ - and $o$-marked questions (lines 4 and 6) consist of M's inference from K's prior turn. The recording of this particular segment occurred around 9 a.m. when M's husband typically has breakfast and chats with friends for hours in the teahouse. In view of K's apparent reluctance to search for his father and ignorance of his father's whereabouts, the ready inference, that K's father is not at the teahouse, conflicts with M's generalized knowledge, captured by $o$ (line 4: The question's preface is a surprise marker 
heh 'what?', intersecting K's attempt to continue his turn). In contrast, line 6 contains a $m i$-marked, straightforward inference.

Both $m i$ and $o$ may stand alone occupying an entire turn (echo questions). Examples (7) and (8) contrast the echo function of $o$ and $m i$.

(7) ((Two female fruit vendors, CW2 and DS, discuss their male friends.))

1 CW2: Go en vennei $n$ ho go en nia he ou beng ney. thing PL today NEG see thing PL come here sit rest PRT 'The folks, today I don't see them come here to sit and rest.'

2 DS: Hm hie ao beng e::h kun-a Zigou:: hie roh he bei-shiu, hm just:now sit rest INT group-PRT Zigou just:now at here that-time

'Hmm just now a group of people, including Zigou, just now they were here.'

3 Gehie beiluei ey no.

he just:now go together PRT PRT

'He (Zigou) had just left with them.'

$4 \rightarrow \mathrm{CW} 2: \quad \boldsymbol{O} ? \quad$ [news receipt + surprise]

$\mathrm{O}$

\section{'Really?'}

5 DS: Hia gang, gang lei o ran.

Just.now say say plan drink liquor

'Just now they were talking about their drinking plans.'

CW2's account (line 1) reveals her lack of prior awareness of DS's account, meriting the use of $o$ in her subsequent turn (line 4). As such, $o$ functions as both a confirmation request and a marker of unexpectedness.

Example (8) contains an instance of $m i$ in a similar context but marking plain information receipt.

(8) ((M and OL chat about a woman in OL's village.))

1 OL: Lelah en so bei rangho: (indistinct)

child PL grow go school

'The children went to school. (indistinct).'

2 ga-er ho bien-nia n dle gong hu lou.

but CLS graduate NEG get work do PRT

'But one didn't find a job after graduation.'

3 Ho biennia gadle gong hu ey.

CLS graduate already get work do PRT

'One has already found a job after graduation.'

$4 \rightarrow$ M: Ben ho mi-a dum ho?

two CLS or three CLS

'(Does she have) two (children) or three (children)?' 
5 OL: Ben ho.

two CLS

'Two.'

$6 \rightarrow \mathrm{M}: \quad \mathbf{M i} ? \quad$ [plain information receipt]

MI

'Is it?'

7 OL: Pongnian ho a, gongde ho a,

girl CLS INT boy CLS INT

'One girl, one boy.'

8 ga-er, ga-er, ba-ni ho de pongnian.

but but the-young CLS COP girl.

'But the girl is the younger one.'

The stand-alone $m i$ in line 6 appears parallel to $o$ in example (7), line 4. Both occur as confirmation requests following an informative turn. However, as shown in line 4, M has already expressed the expectation that the woman has either two or three children. Line 6 simply fine-tunes M's knowledge.

Similar to $m i, o$ may construct rhetorical questions. Unlike the plain inferential façade and resulting "tongue-in-cheek" effect of $m i, o$ 's rhetorical effect arises from knowledge/expectation conflicts, as illustrated in Example (9).

(9) ((Customer no. 28 requests that a bone be trimmed from the meat he is buying.))

1 V: Redie chi wu eyn ho rangchong ying.

If little out PRT NEG know how sell

'If (I) cut out the bone (I) don't know how to sell (it).'

((Three utterances omitted where VR continues to complain.))

2 Dao ra leh.

tease 1SG PRT

'You must be teasing me.'

$3 \quad$ Ziao danggei?

laugh what

'What (are you) laughing for?'

$4 \rightarrow \quad N$ da go chi lo ey ra dli vai go chi ying $\boldsymbol{o}$ ? [inference+incredulity]

NEG cut thing little into PRT 1SG M save thing little sell O

'(If I) don't leave the little thing (=the bone) in the cut, I am going

to save this little thing (=the bone) for (later) sale?'

5 C28: [((laughing))

6 VR: [Zui huaidan.

Most bad

'You're the worst.' 
The $o$-marked question occurs in a conditional construction, interpreting the customer's prior request while also displaying incredulity toward the derived knowledge. That is, by following the request, VR will have to sell the little piece of bone, separately, to another customer (line 4), an entirely nonsensical action. Thus, VR's $o$-marked question is a rhetorical one and functions to reject the request.

\subsection{Ang: property ascertaining and functional linkage to subsequent action}

As Table 2 shows, the discourse features of ang-questions are distinct from the milo pair. Ang utterances do not contain negation, do not append to subclausal propositions, do not attract stance-marking devices, nor do they appear in repetitions of previous utterances. Ang essentially signals a genuine informationseeking query, centering on property establishment. That is, ang ascertains whether the characteristic/situation, represented by the predicate of the utterance, pertains to (i.e., ascribable as a property of) the entity represented by the sentential subject. Property-ascertaining acts provide crucial knowledge, linking to subsequent actions (i.e., the ang-questions launch various "presequences" such as pre-requests, pre-challenges, and pre-services; cf. Schegloff 1998). ${ }^{10}$

Illustrations of ang begin with the most common use of ang in service encounters in data from the roast-duck vendor's stand (among the 40 tokens of ang, 22 [55\%] are from that dataset; among the 22 tokens, 19 [47.5\%] occur in service encounters, 16 among 3 vendors, and 3 from 2 customers). The vendors' 16 ang tokens mark purchase elicitations. Unlike $m i$, which tends to confirm specifics of an order, ang tends to occur at the onset of a service offering, some of which are formulaic, such as ao danggei chi ang? '(Do you want to) bring a bit of something?'. The ang tokens by vendors tend to co-occur with modal verb $d l i$ 'is/are going to', indefinite reference danggei 'something/ anything', diminutive chi 'little', and topic boundary-marking vocatives. Example (10) presents sample ang tokens from two duck vendors:

(10) ((all transaction-initial))

a VR: Nianmei a, ao danggei chi ang?

sister VOC bring what little ANG 'Sister, (do you like to) get a bit of something?'

b C13: Ao hao boh mo nia gal lah! bring head duck CLS come munch PRT '(I'm gonna) get a duck head to munch! (jokingly)'

VR: Ao hao boh mi::? (1.0) Ao ang? bring head duck MI bring ANG '(So you want to) buy duck head? (1.0) (Do you) want (it)?' 
c VR: Ao ang? Ao dangei chi eii?

bring PRT bring what little PRT

'(Do you) like to get (some)? Get a bit of something?'

d VR: Mo dli ao danggei?

you $\mathrm{M}$ bring what

'What do you want?'

nanpong dle kang-a lou ne.

meat-Pong get half-TOP PRT PRT

'There is half of Pong left.'

Ao ang?

bring ANG

'(Would you) get (some)?'

e AS: Whei, mo dli ao danggei ang?

INT 2SG M bring what ANG

'Oh, hello, would you like to get something?'

The five instances of ang occur at the initial boundaries of transactions and, in turn, mark the initial boundaries (note the vocative to attract shoppers' attention in [10a]; the interlocutor's switch from $m i$ to ang after a 1.0 second nonresponse in [10b]; noticing-marker whei in [10e], the nonspecific reference danggei 'what/anything/something' and the diminutive chi 'little' throughout these instances).

The three ang tokens from customers all occur at the initial boundary of a transaction, when customers contemplate qualities of a particular product before placing an order. Example (11) is illustrative.

(11) $((\mathrm{VR}=$ Vendor, $\mathrm{C} 20=$ customer no. 20 . Line 1 is the first utterance in the interaction between $\mathrm{C} 20$ and VR.))

$1 \quad$ C20: $>$ Na en so mo li go^ng?<

DEM PL six CLS each catty

'These are six dollars per catty?'

2 VR: $H e:: h$.

yes

'Yes.'

$3 \rightarrow \mathrm{C} 20$ : Nan na en nà ang? [C20 inquires unknown quality of meat] meat DEM PL hard:to:chew ANG

'Are these hard to chew?'

\section{Go en-}

thing PL

'They-'

$4 \quad$ VR: $N \quad n a ̀$. [VR assures absence of undesirable quality]

NEG hard.

'Not hard.' 
Yan yan en-eey^.

tasty tasty PL-PRT

'Very tasty.'

$6 \rightarrow \quad \boldsymbol{A o} \boldsymbol{A N G}$ ? [VR ascertains C20's intention to purchase]

bring PRT

'Do you want it?'

$7 \quad$ Ao chi mo, heh^?

bring a little $2 \mathrm{SG}$ okay

'(Let me) get you some, okay?'

(3.0)

8 VR: Ao giu-liao?

bring how much

'How much do you want?'

(3.0)

$9 \quad \mathrm{VR}: \quad$ En eey^ $m i^{\wedge}$ ? $a o^{\wedge} m o$ ?

PL PRT PRT bring PRT

'(So you want) these? Get one?'

(1.0)

$10 \quad$ Ao bah na:: kang mi bah biang kang?

bring PRT thick end or PRT thin end

'(Do you) want the thick part or the thin part?'

(3.0)

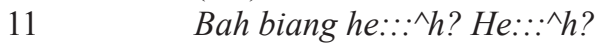

PRT thin PRT PRT

'The thin end, okay? Okay?'

12 $\rightarrow$ C20: En rang $\boldsymbol{n a ̀} \quad \boldsymbol{o}::^{\wedge \wedge}$ ? [C20 seeks reassurance of meat quality] PL NEG hard:to:chew PRT

'They really are not hard to chew?'

13 VR: $N$ nà no::^^ .

NEG hard PRT

'Not hard!'

(2.0)

14 VR: Ao na mo luei lo ey $n$ ao^? $\mathrm{He}^{\wedge} h$ ?

bring DEM CLS PREP into PRT NEG bring PRT

'Get this one in there or not (get) it? What (do you say)?'

15 $\rightarrow \mathrm{C} 20: \quad H e: \cdots h$. [C20 agrees to a purchase]

okay

'Okay.'

The ang question occurs early in the exchange, to ascertain the meat's texture, a property unknown to the customer and critical to the customer's purchase 
decision (evidenced by the lengthy period of indecision [lines 3-15], the vendor's repeated persuasion attempts [lines 4-11] and the customer's seeking re-assurance using $o$ [line 12]). Only after repeated reassurance does C20 agree to a purchase.

Ang not only facilitates service encounters when customers and vendors seek unknown information to prepare for subsequent transactions, but also occurs in ordinary conversation with similar action-preparatory, propertyascertaining features. Example (12), from the dressmaker's shop, illustrates a multilayered information-seeking sequence where the "property-ascertaining" meaning of ang is pivotal for the unfolding discourse.

The episode spans a 25-minute lapse of time, beginning with $\mathrm{M}$ coaxing the dressmaker's kindergarten-age son to accompany her to the market where she will buy sugarcane for him, and ending with $\mathrm{M}$ announcing departure to the market to buy sugarcane.

(12) $\quad((\mathrm{M}=$ researcher's mother-in-law; $\mathrm{D}=$ dressmaker $))$

1 M: ((addressing D's kindergarten-age son. In Mandarin.))

Qu luo. go PRT

'(Let's) go.'

2 D: ((in Shishan))

Ge $n$ guan mai mi::?

SG NEG eat sugarcane PRT

'(So) he doesn't want to eat sugarcane?'

... ((two turns, by M and D, of repeated content, omitted))

3 M: ((in Mandarin, to D's son))

ka::^n kan lo: $u^{\wedge}$, (.) qu bu QU::^?

look look PRT go NEG go

'(Let's) just take a look. (Shall we) go or not?'

((Scene interrupted by passers-by and customers entering the shop and chatting with $\mathrm{M}$ and D. Approx. 20 minutes pass. Feng enters the shop, carrying a bundle of sugarcane. $\mathrm{F}=\mathrm{Feng}, \mathrm{SS}=$ seamstress/employee in the shop.))

$4 \mathrm{M}$ : Eh Feng a, nia ne, mo biang na gei li huan o giu-liao?

PRT Feng VOCcome LOC 2SG buy DEM type each bundle money how:much

'Feng, come here, this you bought (=sugarcane), how much (is it) a bundle?'

5 F: Go en o mo aop roh.

thing PL money CLS five at

'They (are) a dollar fifty.' 
6 M: Mo aop?

CLS five

'A dollar fifty?'

7 F: $\quad M m m$.

$8 \rightarrow \mathrm{M}: \quad$ Go $\quad$ en nong ang? [ascertaining unknown property of sugarcane] thing PL hollow ANG

'Are they hollow?'

$9 \rightarrow \quad[$ Go en nong da ang?

thing PL hollow inside PRT

'Are they hollow inside?'

10 SS: [ Go en dlinong eydino.

thing PL M hollow PRT PRT PRT

'They will have turned hollow by now.' ((=the last sugarcane harvest is January. Current time is May. The sugarcane in the market must be old and turned hollow inside)).

11 Mang ah dli nong da.

fear also M hollow inside

'I suspect they will be hollow inside."

12 Dlong eydei ah dli nong da ey di no

reach now also M hollow inside PRT PRT PRT

'It's been now (May), sugarcanes will have turned hollow inside.'

13 M: $[(($ takes the bundle and weighs it in her hands $))$

[Hmm..... ${ }^{o} \mathrm{kuan}{ }^{\circ}$.

NEG heavy

'Hmm ... not heavy.'

14 F: (indistinct)

Dlong eydei mang $n$ nong da lou di

reach now fear NEG hollow inside yet PRT

'I suspect (sugarcane) hasn't turned hollow by now yet.'

15 D: ((weighs the bundle in her hands))

$\mathrm{Na}$ o mo aop?

only money CLS five

'Only a dollar fifty?'

16 Mai en ni leh.

sugarcane PL small PRT

'The sugarcanes are small.'

((three passers-by came, each chatting with M and D. 45 turns

[approx. 3 minutes] later.)).

17 M: Ge gang-migo-ra bei liu mai en rang-zhong

3SG say what $1 \mathrm{SG}$ go look sugarcane PL how:good

'She said- what- I'm gonna go see how the sugarcanes are.' 
D: Mon biang mai lah.

2SG NEG buy sugarcane PRT

'Don't you buy sugarcane (for my son).'

19 M: Ra bei liu liu eii. [M announces departure to buy sugarcane]

1SG go look look PRT

'I'm just gonna go and take a look.'

Throughout the 25 minutes M's interest to buy sugarcane remains. When F enters the shop with her purchase, the extremely low-priced sugarcane becomes the center of attention. M's echo (line 6) and D's reiteration through the addition of na 'only' (line 15) emphasize the unusualness of the low price. ${ }^{11}$ Two tokens of ang appear in lines 8 and 9. The content of these questions does not repeat previous discourse to seek confirmation, but constitutes new inquiries of a property of the sugarcane unknown to the speaker. $\mathrm{M}$ rephrases the question from line 5 to line 6 by adding the locative $d a$ 'inside', further highlighting a query for unknown information. Subsequently, SS, M, and F each attempt to ascertain the sugarcane's quality, either by assertive deductions (SS's utterances in lines 10-12 and F's in line 14) or using physical evidence (i.e., weighing the sugarcane bundle by hand).

The ang-questions are embedded in two actions: One action is locating an explanatory account after hearing the low price. That is, low quality, if ascertained, accounts for the low price. The other action relates to M's intent to buy sugarcane, emerging at the episode's beginning and ending with $\mathrm{M}$ announcing her departure to buy sugarcane, 25 minutes later. In both cases, ang reflects/originates from M's action-prone intention (discursive or actual), and establishes a crucial knowledge base for subsequent action (cf. Schegloff 1988).

Example (13) further illustrates the "presequence" function of ang occurring with a verbal predicate. Ang effectuates a "property" reading of the event in concern, that is, it focuses on certain experience resulting from eventparticipation rather than the event itself.

(13) ((Prior to this segment, $\mathrm{K}$ has told $\mathrm{BC}$ that his city of residence in the US is smaller than Haikou. $\mathrm{BC}=$ restaurant owner))

1 BC: Ni gua Haikou lou? small pass Haikou PRT '(Even) smaller than Haikou?'

2 K: Heh. Ni gua Haikou. yes small pass Haikou 'Yes, smaller than Haikou.' City 3SG DEM PL every CLS really 
ni di no.

COP small small PRT PRT

'The cities over there (=in the US) are all so small.'

$4 \rightarrow$ BC: Ey mo de bei Niuyo (.) Huadengdun na gei du he

PRT 2SG COP go NewYork Washington

ang?

DEM type sight-see ever PRT

'Have you ever been to New York, Washington (DC), these places, to sight-see?'

5 K: Heh?

okay

'What?'

$6 \rightarrow \mathrm{BC}:$ Mo bei Niuyo Huadengdun na gei he ang?

2SG go New York Washington DEM type ever PRT

'Have you ever been to New York, Washington (DC), these places?'

$7 \quad \mathrm{~K}$ : Dlou ginggua na gei, $n \quad l o d u$.

1PL pass by DEM type NEG into sight-see

'We passed by, like that, didn't go in to sight-see.'

8 BC: Niuyo na gei dli no a.

New York DEM type M big PRT

'New York, these types of places, should be big.'

While providing confirmation that the city of $\mathrm{K}$ 's residence is smaller than Haikou, $\mathrm{K}$ further informs BC that all cities in the United States are small (lines 2 and 3), an understanding possibly biased by K's having lived in a college town for the duration of his US studies. Finding the assertion difficult to accept, BC utilizes ang to ascertain a factual base prior to launching his disagreement/challenge. The ang-marked question concerns whether $\mathrm{K}$ has been to New York, Washington, DC, or other such US cities, all of which, arguably, are not small cities (lines 4 and 6). The verbal predicate, albeit stating events, focuses on K's having first-hand knowledge regarding sizes of cities in the United States. On the basis of the answer, BC would know whether K's assertion is experiential knowledge, or pure assumption. The two instances of he 'ever', and BC's deletion of the mitigator $d u$ 'to sight-see', in the otherwise verbatim repeat of his original question from line 4 to line 6 , instantiate the presequential nature of these questions. Only after K confesses to only having passed by New York (line 7) does BC launch a counter-assertion (line 8).

Thus, ang is a yes/no question device distinct from the mi/o pair. Interrogatively, ang signals a genuine information-seeking question. The core meaning of property establishment leads to employment of ang in various "presequences" in both service encounters and ordinary conversations. 


\section{Discussions and conclusion}

This study analyzes the discourse/pragmatic features of yes/no question particles $m i, o$, and ang in Shishan. Both $m i$ and $o$ signal external information processing, hence encode "contextual evidence bias" (Romero 2005). Mi manifests a simple, linear processing of external information, either constituting plain registrations of new information or simple inferences. $O$ conflates Type I (independent knowledge bias) and Type II (contextual evidence) biases (Romero 2005) by indicating incongruity between processed information and prior knowledge. Subsequently, $o$ expresses a range of affective stances, such as surprise, annoyance, and amazement.

Ang differs from $m i$ and $o$, marking "original" queries from the speaker's own "cognitive environment" (Haegeman 1993; Sperber and Wilson 1995 [1986]). Semantically, ang is a property-ascertaining device (i.e., ascertaining whether the characteristic/experience, as coded in the predicate of the utterance, is ascribable as a property of the entity represented by the sentential subject). In conversation, the semantics of "property ascertaining" facilitates establishment of a factual basis for subsequent speaker action, i.e., ang marks presequences.

The natural class, ang, $m i$, and $o$, comprises part of an elaborate system of polar interrogatives in Shishan. The rising intonation is a significant means for signaling a yes/no question, along with pragmatic particles $e r$ and $a$, tags ( $g a$ 'already?', heh 'okay?', $n$ heh '(not) okay?', n go 'not so?', gang 'say?', $n$ gang '(one) can't say?'), and the V-N-V structure (cf. Note 2). The co-presence of ang/mi/o and other yes/no question devices afford Shishan speakers a full range of interrogative nuances. For instance, $m i$ and $o$ mark external information processing and thus do not signal independently formulated propositions such as independent suppositions awaiting confirmation (e.g., "He's coming I suppose?", Bolinger 1957: 10-11). The pragmatic particles er, $a$, and the rising intonation have the potential of marking independent assertions (cf. Note 8). Further, mi/o/ang are information-central, and thus do not signal suggestion/ action proposals for consent. Such functions see the assistance of various tag elements, particularly heh 'okay?'(cf. Note 7).

In addition, mi/o-marked echoes of the interlocutor's previous turn treat the preceding utterance as informative, leading to the speaker's accruing knowledge (with or without knowledge conflict, with or without rhetorical effect). Thus, mi/o are inappropriate for echoing questions due to mishearing (e.g., "John? [John who?]", cf. Bolinger 1957). In cases of mishearing, the echo repeats the previous turn to signal lacking full grasp of the intended meaning of the previous turn (i.e., "repair sequences," Schegloff et al. 1977). The rising intonation, rather than mi/o, facilitates such repair initiations (cf. Note 11). 
On the side of expressing genuine, information-seeking questions, the V-N$\mathrm{V}$ construction, a common typological feature of Chinese languages and Southeast Asian languages (Li and Thompson 1981; Schaffar and Chen 2001) provides an alternative to ang. While ang, a property-ascertaining device, focuses on a particular property prominently relevant to a subsequent action, the $\mathrm{V}-\mathrm{N}-\mathrm{V}$ construction focuses on the affirmative/negative polarity as a closed set of binary choices. Thus, in cases of the speaker's only interest being if an event will or will not take place, the V-N-V construction is more suitable than ang. For example, in a service encounter, after lengthy price negotiation and painstaking persuasion efforts, the vendor may lose patience and utter, ao $n$ $a o$ ? '(Are you going to) buy (it) or not buy (it)?', to urge a final choice.

Overall, the current case study of $m i, o$, and ang is a step toward understanding the elaborate yes/no question system in Shishan. Arguably, the elaborate yes/no question system is comparable to those in Cantonese, Lao, Taiwanese, Singapore Teochew, Thai, Vietnamese, and other Southeast Asian languages (Cheng 1977; Cole and Lee 1997; Enfield 2007; Iwasaki and Ingkaphirom 2005; Matthews and Yip 1994; McClive 2002). Heritage (2002: 1427) remarked that questions are "social normativity $[\ldots]$ frozen in grammar $[\ldots]$. ." The propensity of Southeast Asian languages to formalize subtle interactional/ pragmatic distinctions suggests the importance local cultures attach to such distinctions. Further study should attend to the yes/no question system of Shishan vis-à-vis other Southeast Asian languages. Through understanding the contrastive features of yes/no question devices across languages of geographical and typological affinity, researchers can gain a thorough view of the extent to which the polar interrogative resources merit sociocultural and cognitive accounts and bear influences from language-contact situations.

\section{Appendix A: Abbreviations}

$\begin{array}{ll}\text { 1SG } & \text { first person singular } \\ \text { 1PL } & \text { first person plural } \\ \text { 2SG } & \text { second person singular } \\ \text { 2PL } & \text { second person plural } \\ \text { 3SG } & \text { third person singular } \\ \text { CLS } & \text { classifier } \\ \text { COP } & \text { copula } \\ \text { DEM } & \text { demonstrative } \\ \text { INT } & \text { interjection } \\ \text { LOC } & \text { location } \\ \text { M } & \text { modal verb } \\ \text { NEG } & \text { negative }\end{array}$




$\begin{array}{ll}\text { PL } & \text { plural marker } \\ \text { PREP } & \text { preposition } \\ \text { PRT } & \text { particle } \\ \text { RES } & \text { resultative } \\ \text { TOP } & \text { topic marker } \\ \text { VOC } & \text { vocative }\end{array}$

\title{
Appendix B: Transcription conventions
}

\author{
[ Overlapping utterances \\ [ \\ $=\quad$ Contiguous utterances \\ (.) (2.0) Intervals within and between utterances \\ - Untimed pause \\ (( )) The conversational background indicated by double parenthesis \\ Boldface Indicates features of interest of the researcher
}

Characteristics of speech delivery (elongation, falling intonation, rising intonation, increased volume, stress, and contour):
CAPS Increasing volume
colo:::n Elongation
$\wedge \quad$ Pitch peak

\section{Notes}

* I would like to thank the anonymous Text \& Talk reviewers for their critical comments and very helpful suggestions. I am deeply indebted to Dr. Susan Strauss whose insights and intellectual guidance have not only helped to shape the paper, but also render the process of research and writing an experience of growth and enjoyment. I thank Dr. James Lantolf, Dr. Philip Baldi, and Dr. Jessica Williams for very helpful suggestions and comments on early versions of the analysis. I am grateful to Mr. Roger Dudik for editorial assistance and Jiaqiang Chen for Shishan data consultation. I owe much to the Shishan community whose support made the research project possible. All faults, omissions, and mistakes are the author's.

1. The example in Romero (2005) only manifests Type II epistemic bias as a contextualized interpretation of an otherwise generic interrogative form.

2. Mi,o, and ang are situated in an elaborate yes/no question system. The current data contain 439 yes/no questions with 230 (52.4\%) instances of milo/ang. The following interrogative devices co-exist with the milo/ang set: (i) rising intonation, 106 instances, $24.1 \%$ in the current data; (ii) tags (e.g., $n$ go? 'Isn't it?'; heh? = 'okay?'), 40 instances, 9.1\%; (iii) pragmatic particles $e r$ and $a, 40$ instances, $9.1 \%$; (iv) the verb-not-verb (V-N-V) structure, 12 instances, $2.7 \%$; (v) question particles borrowed from neighboring languages (e.g., Hainanese $d a$ and Mandarin $m a$ ), 11 instances, $2.5 \%$. 


\section{Xuehua Xiang}

3. Although Shishan is not a Chinese language, its sound system is broadly similar to Mandarin. The choice of Pinyin as the tool for romanizing Shishan is due to the practical consideration of familiarity with the Pinyin system, and the official language of Shishan being Mandarin, leading local residents to be familiar with only Pinyin-based Romanization.

4. Particles in embedded questions ( 9 cases of ang) are excluded since they represent phenomena worthy of separate attention. Compound particles, where one or more than one particle follow ang/mi /o (11 cases with ang, and 6 cases with $m i$ ), are excluded, following the argument that compound particles form meanings distinct from individual particles (Luke 1990). Omission of these instances does not affect the current arguments.

5. An earlier version of the analysis appears in Xiang (2006), which also includes an analysis of the rising intonation as a polar interrogative device. The current version is a substantial development from the original analysis.

6. An anonymous reviewer suggested the term "simple inference" now incorporated into the meaning proposed for $m i$.

7. Example (2) contains two instances of yes/no questions marked by the tag heh (line 1) and pragmatic particle $a$ (line 5). Both utterances, rather than information-seeking, propose an action seeking consent. The lexical origin of heh 'okay' is the adjective heh 'good'. Particle $a$ occurs in declarative utterances, $w h$-questions, and yes/no questions where $a$ has a higher pitch.

8. Example (3) (line 1) contains a yes/no question marked by the pragmatic particle er. Different from $m i$, the $e r$-question marks the speaker's independent assertion rather than "reading" contextual evidence. Further, $e r$, similar to $a$, is a pragmatic particle in nature which may also occur in declarative statements and $w h$-questions.

9. M's utterance (line 4) is an alternative question, two noun phrases joined by the alternative question marker, mi(a). The current data contain $31 \mathrm{mi}(a)$-marked alternative questions. Further study would ascertain whether $m i(a)$, as an alternative question marker, relates to the question marker $m i$ through grammaticalization.

10. The 40 ang tokens provide a small dataset for the current analysis. In addition, 22 of the total 40 ang tokens (55\%) occur in the dataset from the duck vendor, primarily in service encounter discourse. The lack of access to visual aspects of the conversation recorded at the roast duck vendor's stand limits the interpretation of the data. Although this skew does not affect the current analysis, further study in broader contexts and including access to multimodality of the interaction would be valuable.

11. Both the utterances in line 6 and line 15 are echo questions marked by rising intonation alone. The distinction between mi/o versus the rising intonation in marking an echo question lies in the speaker's orientation to the preceding utterance. Bolinger's (1957) analysis of the English yes/no questions distinguished between echoes that are quotative ("He is coming? [Is that what you said]?") versus echoes through which "the speaker makes the stimulusutterance his [sic] own" (1957: 26) (e.g., "He is coming, really?"). Mi/o-marked echoes are similar to the latter case discussed in Bolinger (1957). Both particles hold the previous utterance as informative from which to derive knowledge. The echo questions in line 6 and line 15 "quote" F's previous utterance in disbelief, as if doubting one has correct hearing. Further study of the rising intonation would verify the current hypothesis.

\section{References}

Atkinson, J. Maxwell \& John Heritage. 1984. Structures of social action: Studies in conversation analysis. Cambridge, MA: Cambridge University Press. 
Bolinger, Dwight L. M. 1957. Interrogative structures of American English: The direct question. Tuscaloosa: University of Alabama Press.

Chafe, Wallace. 1994. Discourse, consciousness, and time: The flow and displacement of conscious experience in speaking and writing. Chicago: The University of Chicago Press.

Cheng, Robert L. 1977. Taiwanese question particles. Journal of Chinese Linguistics 5(2). 153 185.

Cole, Peter \& Cher L. Lee. 1997. Locality constraints on yes/no questions in Singapore Teochew. Journal of East Asian Linguistics 6. 189-211.

Comrie, Bernard. 1984. Russian. In W. S. Chisholm (ed.), Interrogativity, 7-46. Philadelphia \& Amsterdam: John Benjamins.

Enfield, Nicholas J. 2007. A grammar of Lao. Berlin \& New York: Mouton de Gruyter.

Givón, Talmy. 2005. Context as other minds: The pragmatics of sociality, cognition and communication. Philadelphia \& Amsterdam: John Benjamins.

Haegeman, L. 1993. The interpretation of the particle da in West Flemish. Lingua 90. 111-128.

Heritage, John. 1984. A change-of-state token and aspects of its sequential placement. In J. M. Atkinson \& J. Heritage (eds.), Structures of social action, 299-345. Cambridge: Cambridge University Press.

Heritage, John. 2002. The limits of questioning: Negative interrogatives and hostile question content. Journal of Pragmatics 34. 1427-1446.

Hinds, John. 1984. Japanese. In W. S. Chisholm (ed.), Interrogativity, 145-188. Amsterdam \& Philadelphia: John Benjamins.

Itani, Reiko. 1993. The Japanese sentence-final particle ka: A relevance-theoretic approach. Lingua (90). 129-147.

Iwasaki, Shoichi \& Preeya Ingkaphirom. 2005. A reference grammar of Thai. Cambridge, MA: Cambridge University Press.

Koshik, Irene. 2002. A conversation analytic study of yes/no questions which convey reversed polarity assertions. Journal of Pragmatics 34. 1851-1877.

Li, Charles N. \& Sandra A. Thompson. 1981. Mandarin Chinese: A functional reference grammar. Berkeley, CA: University of California Press.

Li, Charles N. \& Sandra A. Thompson. 1984. Mandarin. In W. S. Chisholm (ed.), Interrogativity, 47-62. Amsterdam \& Philadelphia: John Benjamins.

Lyons, John. 1977. Semantics, vol. 2. New York: Cambridge University Press.

Matthews, Stephen \& Virginia Yip. 1994. Cantonese: A comprehensive grammar. New York: Routledge.

McClive, T. 2002. The question of Không: Use and effects of the Vietnamese negative and interrogative U:ber-Particle. Papers from the Tenth Annual Meeting of the Southeast Asian Linguistics Society, 233-246. Arizona State University, program for Southeast Asian Studies.

Quirk, Randolph, Sidney Greenbaum, Geoffrey Leech \& Jan Svartvik. 1985. A comprehensive grammar of the English language. London: Longman.

Rakic, Stanimir. 1984. Serbo-Crotian yes/no- questions and speech acts. Journal of Pragmatics 8. 693-713.

Romero, Maribel. 2005. Two approaches to biased yes/no questions, 352-360. In John Alderete et al. (eds.), Proceedings of the 24th West Coast Conference on Formal Linguistics. Somerville, MA: Cascadilla Proceedings Project.

Schaffar, Wolfram \& Lansun Chen. 2001. Yes-no questions in Mandarin and the theory of focus. Linguistics 39(5). 837-870.

Schegloff, Emanuel A. 1988. Presequences and indirection: Applying speech act theory to ordinary conversation. Journal of Pragmatics 12. 55-62.

Schegloff, Emanuel A., Gail G. Jefferson \& Harvey Sacks. 1977. The preference for self-correction in the organisation of repair in conversation. Language 53. 361-382. 


\section{0}

Slobin, Dan I. \& Ayhan A. Aksu-Koç. 1982. Tense, aspect, modality, and more in Turkish evidentials. In Paul Hopper (ed.), Tense-aspect: Between semantics and pragmatics, 185-200. Amsterdam \& Philadelphia: John Benjamins.

Sperber, Dan \& Deidre Wilson. 1995 [1986]. Relevance: Communication and cognition. Oxford: Blackwell.

Strauss, Susan. 2005. Cognitive realization markers in Korean: A discourse-pragmatic study of the sentence ending particles -kwun, -ney, and -tela. Language Sciences 27(4). 437-480.

Strauss, Susan \& Xuehua Xiang. 2009. Discourse particles: Where cognition and interaction intersect-The case of final particle ey in Shishan dialect (Hainan Island, P.R. China). Journal of Pragmatics 41. 1287-1312.

Xiang, Xuehua. 2006. A discourse-pragmatic study of interactional particles in Shishan (Hainan Island, P.R. China). University Park, PA: Pennsylvania State University doctoral dissertation.

Xiang, Xuehua. 2009. Addition and reassessment: Preverbal particle "ah" in Shishan (Hainan Island, China). Text \& Talk 29(1). 99-124.

Xiang, Xuehua. 2011. Constraint reality: Linguistic expressions of restrictivity and emotive stances: A discourse-pragmatic study of utterance-final lah in Shishan (Hainan Island, China). Lingua 121(8). 1377-1400.

Xuehua Xiang is Assistant Professor of Applied Linguistics in the Department of Linguistics at the University of Illinois at Chicago. She received her Ph.D. in applied linguistics from the Pennsylvania State University. Her research interests include interaction and grammar, grammar and cognition, second language writing, second language curriculum and materials development. Address for correspondence: Department of Linguistics, University of Illinois at Chicago, University Hall 1713, MC 315, Chicago, IL 60607, USA 〈xxiang@uic.edu〉. 
Copyright of Text \& Talk is the property of De Gruyter and its content may not be copied or emailed to multiple sites or posted to a listserv without the copyright holder's express written permission. However, users may print, download, or email articles for individual use. 